\title{
ADVANTAGES AND CHALLENGES OF USING COMPONENT- BASED SOFTWARE DEVELOPMENT IN THE VISION OF BUILDING A MODERN EDUCATIONAL SYSTEM
}

\author{
Irina-Miruna RADU \\ Bucharest University of Economic Studies, Romania \\ miruna.radu@outlook.com
}

\begin{abstract}
Nowadays the educational system does not benefit from all the current technological developments. Taking into account the problems that the system faces, it is important to analyze a solution keeping these developments in mind. This paper proposes to analyze componentbased software development as a solution for the future of an e-educational system. Component-based software development is a methodology that encourages the idea of building independent pieces of software with a defined purpose that can be used and reused both in different applications as well as on their own. Throughout the study the major advantages and challenges that appear repeatedly in different research papers and articles are highlighted always referring to the issues that the current educational system is dealing with such as the lack of funds and teacher empowerment, the lack of access to new trends and the lack of updated curricula and personalized learning paths for the pupils. This study can be used as a starting point for someone who wants an overview over how CBSD is seen and what competitive advantages and challenges would come across when choosing this solution for the development of an educational application.
\end{abstract}

Keywords: component-based software development, e-education, CBSD

JEL classification: L86

DOI: $10.12948 / \mathrm{ie} 2019.04 .10$

\section{Introduction}

The world we live in is in a continuous sprint for technological innovation trying to discover and technologize more, in a shorter time, with fewer resources. The applications that are requested nowadays are exponentially more complex than the ones in the past, humans being on a run to technologize every aspect of their life, even our body. [1] Taking this into consideration the programmers have to think about a solution. The one proposed by this paper is about turning more towards the spirit of software reutilization by using a component way of thinking.

The e-education is also an important aspect of people's life that is part of this revolution of technology. As the new generations are born in a technologized world, a generation known as the digital native generation, it is clear that the old ways of teaching needs to be improved by embracing a way for e-learning and the forming of e-skill in the lives of the pupils.

But the road to e-education may prove to be a long one considering that the teaching styles, curricula and the particular needs for each child vary so greatly from area to area or from one institution to the other. To get to the point where the expectations are met, a lot of effort is needed. On these grounds, the need to introduce a mindset of software reuse in e-education system development as well is unquestionable.

This article intends to propose a software reuse way of thinking in the development of eeducation. Hence this paper aspires to trace out and synthetize the main advantages and 
challenges that component based-software development has, as they emerged throughout the last years from different publications. The benefits will be analyzed and the issues will not be lost from focus, all in the vison of building a new environment of collaborative development for educational software. It is expected that by the end of this article the readers can reach their own conclusion if the advantages of component based development can outweigh their disadvantages when it comes to choosing CBSD for educational applications.

\section{Understanding what CBSD means}

More than fifty years ago, Mcllory [2] proposed that the world of software development should borrow the idea of commercial component production from the engineering fields. This led to Component-Based Software Engineering (CBSE) methodology, also known as componentbased software development (CBSD). Nowadays, CBSD encourages the idea that, just like Lego pieces software systems can be built from existing components, components which were developed keeping the purpose of reutilization in mind [3] .

Therefore, in the component thinking spirit, the development team starts from the systems' requirements and tries to cover most of them with components that already exist on the market. For the more specific needs of the product, the developers create the necessary parts as standalone pieces that respond to certain purposes and that can be used and reused over time to build something new. For the success of this architecture the parts must be well documented, with less to no effort to understand, accessible for deployment, simple to update to recent versions and painless to replace by other parts.

These parts are called components and the literature has a few definitions for them. Some people define software components as being a platform free, neutral language, encapsulated container that can be accessible from the outside through an interface [4]. Microsoft Corporation emphasize that a component is a unit ready for packaging, distribution or delivery that brings services within encapsulation boundary or data integrity. A [5] software component is seen as a unit that has an interface following some clear specifications and designed for a certain context, having some specified dependencies. Moreover, a software component can be deployed as a standalone part, independently. To summarize a software component is a piece with a well-defined interface which is platform free, reusable and encapsulated to be ready for distribution and delivery independently from other components. In addition, it is important to remember that a component is built to solve a need, a certain scenario of utilization.

\section{Research method}

To achieve the goal of the paper, all the needed information was gathered through a three-step review process. For start, databases like Google Scholar, Science Direct and others were searched for publications newer than 2010 and contained the following keywords: „component-based software development", "component-based software engineering“, "advantages", "challenges", "disadvantages" in the title. In the second step all the abstracts were analyzed and the studies that did not respond to expectations were rejected from the research. In the last step, every article was deciphered and only for the ones that were considered relevant, the advantages and disadvantages were extracted in order to draw the attention to the most important ones.

To accomplish this paper purpose a quantitative approach was used. Multiple research papers, 10 papers for the advantages and 7 for the challenges, where analyzed to present a closer to reality overview and to lead to a conclusion on the impact that CBSD can have on the construction of an application that can change the way the education system is seen, by taking care of some of its needs. 
www.conferenceie.ase.ro

\section{E-education needs}

Modern education requires the use of new tools to achieve the desired effect on the new generations. To be able to deliver solutions that can emerge to market and gain lots of supporters it is important to know the issues and needs of the system. The problems the educational system faces seem to be similar throughout the globe. As seen in [6] [7] [8] the problems can be summarized as:

- lack of funds and other resources: lots of intuitions are faced with having poor infrastructure and equipment, less human power than needed and less funds to be able to undertake the change they need

- lack of executive power for the teachers: the teachers have no saying when it comes to important decisions. Furthermore, when having innovative ideas teachers need to go up against the administrative and management office to convey the importance of that change

- lack of access to development: for teachers is hard to get access to different courses and trends to develop special skills to be prepared for the e-education

- lack of curricula updates: the curricula is outdated, not focusing on the creative thinking skills critical for the digital native generation, but on the ability to memorize and stock information that doesn't add much value nowadays

- lack of personalized learning paths: every child is different and therefore the way he discovers and learns new things is also unique. To come to his aid the educational system must be able to offer personalized learning paths that can help him evolve faster

\section{Major benefits of CBSD}

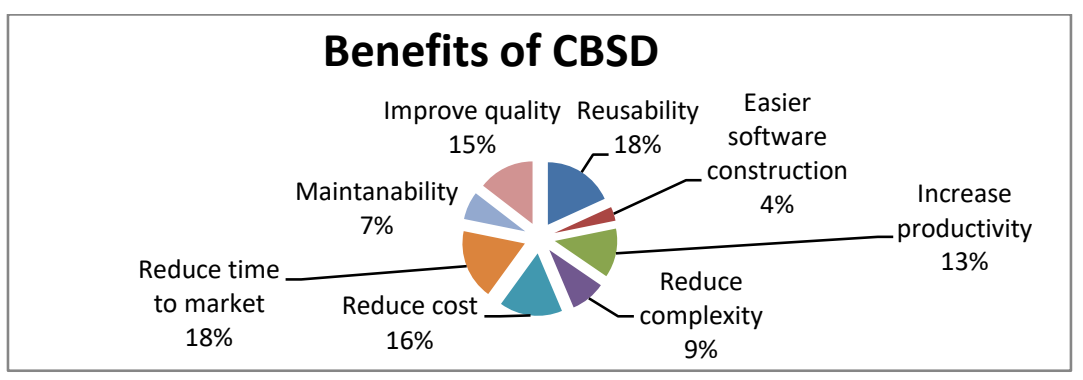

Figure 1. Benefits of CBSD

As shown in Figure 1 the advantages that are reiterated most through the selected articles are: reusability, reduction of time to market, cost reduction, quality improvement.

\subsection{Increase in reusability}

The concept of reusability in CBSD it is based on the usage of different components and assembling them for different purposes. [9] Components are developed for specific needs and they can be used by different applications. In some cases, they can even be updated to correspond to new requirements.

In the perspective of building an educational application this concept can really be helpful by building a market of components specialized on different school subjects or exercise types that later can be reused with the hope of creating the best e-educational system for our children, a system that is able to deliver personalized learning paths based on pupil needs.

\subsection{Reduction of development time}

When talking about building an application for which some or most of the components already exist on the market it is clear that the amount of time necessary during the development phase 
would be much less compared to building a totally new application from scratch with all the designing, coding and testing involved into it. Besides, if the components already exist in other environments, it is easier to introduce the application to market because they have already been validated under those conditions.

In a continuously changing world it is important that the educational software keeps up with the changes. Being able to take components that already exist and put them together to develop an application in a really short time is exactly what education needs.

\subsection{Cost Reduction}

It is highlighted that CBSD can really impact the costs related to development. Instead of building software from zero, the development is based on integrating pre-fabricated software components [10]. This means less resources such as time and people needed for building the application, which leads to savings.

Bearing in mind that the main problem of the educational system is the lack of funds, having the possibility to build software at lower costs is always a good choice.

\subsection{Improvement of quality}

The quality of software in the case of CBSD depends largely on the quality of its individual components [11]. Considering that most of the components have been developed in different teams and are used by different applications I would like to think that the quality is assured and validated by being on the market for a while and being tested in different configurations.

Having a good quality application is important in gaining a good reputation on the market. And as the education system has access to limited resources as mentioned above, a good reputation derived from good quality would lead to better visibility to different institutions.

\section{Major challenges of CBSD}

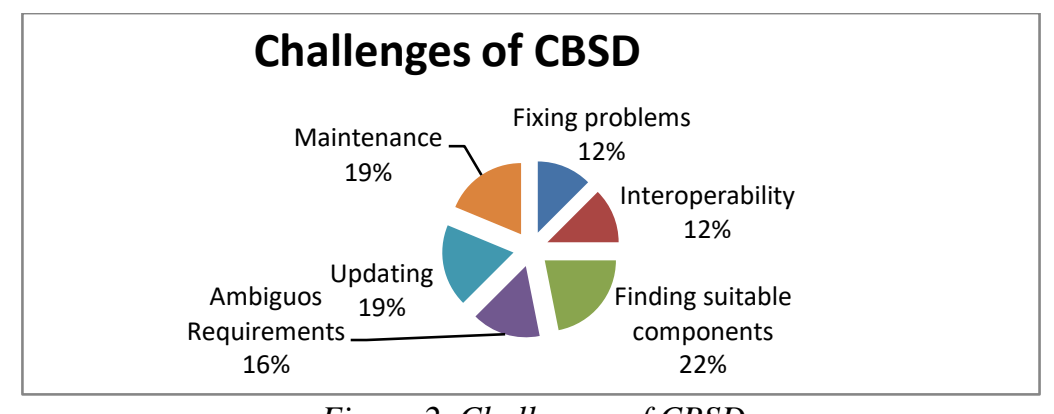

Figure 2. Challenges of CBSD

As shown in Figure 2 the most reiterated challenges are regarding finding the right components, updating and maintaining the components, ambiguous requirements and fixing problems.

\subsection{Choice of components}

The biggest difficulty a developer has to face when it comes to CBSD is identifying the proper components that can cover all the requirements of the product. As the market is limited, it is hard to find something that will cover the needs one hundred percent. As [12] mentioned before, this problem can be overpowered by picking the right components from the available pool of choices and trying to cover most of the requirements that were negotiated with the stakeholders.

It is clear that when it comes to component reusability, the generality, scalability and adaptability are really important and therefore the investment in it is more demanding. 
www.conferenceie.ase.ro

\subsection{Updating \& Maintenance}

When thinking of CBSD one must have in mind that while the overall maintenance costs can be less than a totally new software, the individual component maintenance price can be higher since the component must be ready to face different needs, different environments and even different types of customers with different expectations towards quality and support [13].

Moreover, when changing parts of the application and updating the system components it is necessary to find replacements for the existing parts or try to figure out what needs to be modified. Sometimes, the components are external and the in-house knowledge is little. Also if the components are developed into a black-box method nothing can be done to adapt them to the necessities of the application.

\subsection{Ambiguous requirements}

The managing, defining and refining requirements are an important chapter in the development process. CBSD components make no exception to this. The CBSD components are developed with the purpose of reutilization, which means that they have to be packaged for reused in different types of applications. Therefore, after the requirements are collected and analyzed, the best path to a generalized version of the component has to be chosen [13] .

\subsection{Fixing problems}

When testing an application, the final aim is to know that the customer needs are covered without any problems and at an accepted level of quality. The lack of detail regarding the source code that appears in the case of external components makes tracking errors an actual problem. Furthermore, if some bugs are found in components with vendors unwilling to deliver fixes, the developers have a difficult time trying different workarounds to find fixes and sometimes the only solution is to change the entire component.

\section{Conclusion}

As the world we live in is rapidly evolving so should the systems that are the base of our civilization. I believe the educational system is of utmost importance as it building the next generations. As underlined in this paper the CBSD can really help the system step up by also keeping an eye on the current problems such as lack of funds and teacher empowerment, lack of access to resources, curricula updates and personalized learning paths. From reducing development time to reducing costs, increasing quality and even increasing reusability, the advantages of CBSD cannot be overlooked when it comes out to building the future of eeducation. However in this study we have not omitted challenges such as choice of components, difficulty in updating, maintenance, testing and ambiguous requirements as they to paint a clear vision of the real life and of the disadvantages that have to be considered.

This research has managed to lay out the most important advantages that can be achieved by overcoming the challenges that derive from CBSD, both of which have been mentioned in the specialized literature. Based on this study we can conclude that CBSD is the right choice to make in order to improve the development of educational software considering all the problems this system faces.

\section{References}

[1] B. Luncefor, "Posthuman Visions: Creating the Technologized Body," Explorations in Media Ecology, vol. 11, no. 1, pp. 7-25, March 2012.

[2] M. D. McIlroy, "Mass-produced software components," in Software Engineering Concepts and Techniques (1968 NATO Conference on Software Engineering), New York, Van Nostrand Reinhold, pp 138-155, 1976. 
www.conferenceie.ase.ro

[3] C. Szyperski, "Component Software: Beyond Object-Oriented Programming (2nd)," Boston, MA, USA: Addison-Wesley Longman Publishing Co., 2002.

[4] M. Goulão, "CBSE: a Quantitative Approach," in PhD Workshop at ECOOP, Darmstadt, Germany, July, 2003.

[5] H. Washizaki, H. Yamamoto and Y. Fukazawa, "A Metrics Suite for Measuring Reusability of Software Components," in Proceedings of the 9th International Symposium on Software Metrics, Sydney, Australia, September 2003, pp 211-223.

[6] N. Onofrei, "The verdict of education experts on the Romanian education system: nepotism, underfinancing, inadequacy," 21 June 2016. [Online]. Available at: https://adevarul.ro/educatie/scoala/verdictul-expertilor-educatie-sistemul-romanescinvatamant-nepotism-subfinantare-inadecvare1_576955105ab6550cb8299d92/index.html. [Accessed 4 March 2019].

[7] K. T. Boyes, "Why our education system needs to change," 4 September 2018. [Online]. Available at: http://www.karentuiboyes.com/2018/09/why-our-education-system-needsto-change/. [Accessed 4 March 2019].

[8] P. Gupta, "Innovation in Teacher Education," International Journal of Recent Research Aspects, Special Issue Conscientious Computing Technologies, pp. 964-966, April 2018.

[9] A. I. Khan, N.-u.-. Qayyum, U. A. Khan, "An Improved Model for Component Based Software Development," Journal of Software Engineering, vol. 2, no. 4, pp. 138-146, 2012.

[10] T. Vale, I. Crnkovic, E. S. d. N. Almeida, P. A. d. M. Silveira, Y. C. Cavalcanti, S. R. d. L. Meira, "Twenty-eight years of component-based software engineering," Journal of Systems and Software, vol. 111, no. January 2016, pp. 128-148, 2016.

[11] P. Banerjee and A. Sarkar, "Quality Evaluation of Component-Based Software: An Empirical Approach," I.J. Intelligent Systems and Applications,, vol. 12, no. December 2018, pp. 80-91, 2018.

[12] A. I. Khan, M. M. Alam, Noor-ul-Qayyum and U. A. Khan, "Empirical Study of an Improved Component Based Software Development Model using Expert Opinion Technique," International Journal of Information Technology and Computer Science, vol. 08, no. July 2013, pp. 1-14, 2013.

[13] S. Singh, A. Singh, Samson and S. Singh, "Component Based Software Engineering," International Research Journal of Engineering and Technology, vol. 3, no. 5, pp. 448-454, 2016. 